\title{
A Simple Gold Nanoprobe Assay for the Identification of Staphylococcus Aureus, Listeria Monocytogenes and Salmonella Enteritidis in Food Specimens
}

\author{
Dimitra Panagiotis Houhoula ${ }^{1}$, Ekatherina Charvalos ${ }^{2}$, Spyros Konteles ${ }^{1}$, Stamatis Koussissis ${ }^{1}$, Vladimiros \\ Lougovois $^{1} \&$ Joseph Papaparaskevas $^{3}$ \\ ${ }^{1}$ Department of Food Technology, Technological Educational Institution of Athens Agiou Spyridonos St, 12210, \\ Aegaleo, Greece \\ ${ }^{2} 2$ Central Labs, Iaso Hospital, 12152, Greece \\ ${ }^{3}$ Department of Microbiology, Medical School, National and Kapodistrian University of Athens, 11527, Athens, \\ Greece
}

Correspondence: Dimitra Panagiotis Houhoula, Department of Food Technology, Technological Educational Institution of Athens Agiou Spyridonos St, 12210, Aegaleo, Greece. E-mail: itsahouhoula@ gmail.com

Received: May 2, 2017 Accepted: June 13, $2017 \quad$ Online Published: July 2, 2017

doi:10.5539/jfr.v6n4p134 URL: https://doi.org/10.5539/jfr.v6n4p134

\begin{abstract}
In the present study, we developed a gold nanoprobe assay, which relies on the colorimetric differentiation of specific DNA sequences, based on different aggregation profiles. We evaluated the assay on DNA extracted from pathogen cultures and from contaminated food specimens. The targets used were the femA gene for the identification of Staphylococcus aureus, the hly gene of the Listeria monocytogenes listeriolysin and the invA sequence for Salmonella spp. Comparison was performed with the reference assay, as described in the respective ISO guidelines for each pathogen, and a direct PCR amplification and detection. The minimum detection limit of the assay was defined at $123 \mathrm{fg} / \mu \mathrm{L}$ DNA, for all species, lower than PCR detection. Specificity was $100 \%$. Sensitivity was $100 \%$, as compared to the reference method, whereas the sensitivity of PCR was $93.3 \%$. The evaluated assay could be used as a sensitive screening method, which does not require major infrastructure, for the detection and identification of pathogens in food specimens. In addition, it can accommodate detection of multiple species, thus allowing multiplexing and expedite turnaround time.
\end{abstract}

Keywords: gold nanoparticles, foodborne pathogens, Listeria monocytogenes, Staphylococcus aureus, Salmonella spp.

\section{Introduction}

Food borne bacterial infections are a continuing challenge to human health world-wide. Over the past two decades, changes of the epidemiology of food borne infections have been reported as a consequence of changes in the social environment and the ability of pathogens to adapt to new niches (Newell et al., 2010). In that respect, the continuous monitoring and surveillance of the pathogens is vital for food safety, clinical diagnosis and therapeutic decisions, and prevention strategies. To date, the existing technology for the detection of food-borne pathogens only meets the criteria of speed, sensitivity, and specificity when it uses large, laboratory-based, sophisticated and costly equipment (Hoorfar, 2011) Therefore, the development of a simplified, cost-effective and accurate procedure for detection of trace amounts of bacterial pathogens, which does not require complex instruments, seems to be imperious in order to overcome the time delay and allow rapid and sensitive detection (McGrath, Elliot, \& Fodey, 2012) in infrastructure deprived environments. Nanotechnology, and more specifically gold nanoparticle chemistry, provides opportunities for the rapid and simple diagnosis of many infectious diseases, being able to detect trace amounts of bacteria, due to their uniqueoptical properties (Agasti et al., 2010; Syed \& Bokhari, 2011). In the present study we developed and evaluated a gold nanoprobe assay, which does not require the amplification of the target DNA, but relies on the hybridization of the pathogen's DNA with gold nanoprobes with subsequent colorimetric differentiation. Subsequently, we compared the assay for sensitivity, specificity, user-friendliness, and infrastructure-independency, to the reference ISO detection method of Staphylococcus aureus, Listeria monocytogenes and Salmonella spp. in food samples, and 
furthermore to PCR detection and identification of these pathogens.

\section{Method}

\subsection{Food Specimens}

During the study period, a total of 60 food specimens from the food industry were collected. All samples were positive by a reference microbiological conventional culture (ISO 6573:2002 for Salmonella spp., ISO 6888-1:1999 for S. aureus, and ISO 11290-1:1996 for L. monocytogenes) assay for at least one of these pathogens causing food-borne infections.

\subsection{Gold Nanoparticle Preparation}

Gold nanoparticles (AuNPs) size $20 \mathrm{~nm}$, were purchased commercially (BBI Solutions, Cardiff, UK). The following oligonucleotides pairs (OLG) were used: (a) 5'-CTT-ACT-TAC-TGG-CTG-TAC-CTG-3' and 5'-ATG-TCG-CTT-GTT-ATG-TGC-3', corresponding to a 686 bp fragment of the femA gene of $S$. aureus, (b) 5'-CAT-TAG-TGG-AAA-GAT-GGA-ATG-3' and 5'-GTA-TCC-TCC-AGA-GTG-ATC-GA-3', corresponding to a $732 \mathrm{bp}$ fragment of the hly gene encoding the pore-forming listeriolysin of L. monocytogenes and (c) 5'-TAT-CGT-ACT-GGC-GAT-ATT-GGT-GTT-TA-3' and 5'-GGA-CAA-ATC-CAT-ACC-ATG-GCG-AGT-CA-3', corresponding to a 540 bp fragment of the invA sequence of Salmonella spp. (Vannuffel et al., 1995; Gouws \& Liedeman, 2005; Vasquez-Novel et al., 2005). All OLG were thiolated (modified with 10xdATP) in the 5'-end of the primer. The AuNP merging with the OLG was performed by adding $1 \mathrm{ml}$ of an aqueous solution of AuNPs to 4 nmol of the thiolated OLG pair (forward and reverse primer) using a previously described protocol (Hill \& Mirkin, 2006). Briefly, each pair of thiol modified OLG was incubated with the AuNPs at room temperature, overnight. The solution was then brought to phosphate buffer $9 \mathrm{mM}, \mathrm{pH} 7$, and subsequently a $0.1 \%$ (w/v) solution of Sodium Dodecyl Sulfate (SDS - Sigma-Aldrich, Life Science Chemilab S.A., Greece) was added. The total salting buffer, $2 \mathrm{M} \mathrm{NaCl}$ in $10 \mathrm{mM}$ Phosphate-buffered Saline (PBS - Sigma-Aldrich, Life Science Chemilab S.A., Greece) was divided in six doses, and was added over the next 48 hours. After centrifugation, the precipitate was washed with $500 \mu \mathrm{l}$ of $10 \mathrm{mM}$ PBS (Sigma-Aldrich, Life Science Chemilab S.A., Greece) pH 7.4, $150 \mathrm{mM} \mathrm{NaCl}, 0.1 \%$ SDS (Sigma-Aldrich, Life Science Chemilab S.A., Greece), and it was re-centrifuged and re-suspended in $500 \mathrm{ml}$ of the same buffer. In that respect, three different AuNP-OLG solutions were prepared, corresponding to each one of the three pathogens, and were stored at room temperature (Hill \& Mirkin, 2006).

\subsection{DNA Extraction from the Isolates}

DNA extraction was performed from a 24h culture of the strains S. aureus ATCC 29213, S. aureus ATCC 25923, L. monocytogenes NCTC 10357 and a clinical S. enteritis strain isolated from a patient with gastrointestinal infection (fully characterized at the National Salmonella Reference Centre), using the NucleoSpin Tissue kit (Macherey-Nagel, GmbH and Co. Germany) according to the manufacturer's instructions, with the addition of a Proteinase $\mathrm{K}$ overnight incubation step at $65^{\circ} \mathrm{C}$. The extracted DNA was designated positive control and was quantified using a spectrophotometer at $260 \mathrm{~nm}$ and subsequently serial ten-fold dilutions were prepared in order to evaluate the analytical sensitivity of the PCR method. Extracted DNA (as described previously) from a $24 \mathrm{~h}$ culture of Escherichia coli ATCC 25922, and a clinical Yersinia enterocolitica strain (designated specificity controls), was used for specificity confirmation. Extraction was additionally performed using an equivalent volume of $10 \mathrm{mM}$ PBS solution (designated negative extraction control).

\subsection{DNA Extraction from the Food Specimens}

The food specimens were subjected to DNA extraction using the NucleoSpin Food kit (Macherey-Nagel, GmbH \& Co. Germany) according to the manufacturer's instructions, with the addition of a Proteinase K overnight incubation step at $65^{\circ} \mathrm{C}$, followed by DNA quantification, as described in the previous section.

\subsection{PCR Amplification}

PCR was performed according to previously published protocols (Vannuffel et al., 1995; Gouws \& Liedeman, 2005; Vasquez-Novel et al., 2005) in $50 \mu \mathrm{l}$ final volume, using the GoTaq Hot Start Master Mix (Promega Gmbh, 68199 , Germany), $1 \mathrm{mM}$ each of the primers and $10 \mu \mathrm{l}$ of eluted DNA. PCR products were separated in a $2 \%$ agarose gel, stained with ethidium bromide $(0.5 \mu \mathrm{g} / \mathrm{ml})$ and documented under UV illumination.

\subsection{Hybridization and Colour Detection}

Hybridization on the extracted DNA from the isolates with the AuNP-OLG solution was performed by adding 10 $\mu \mathrm{L}$ of eluted DNA to $10 \mu \mathrm{l}$ of the solution, followed by two incubation steps, five minutes at $95^{\circ} \mathrm{C}$, and five minutes at $55^{\circ} \mathrm{C}$ for $S$. aureus, L. monocytogenes and $60^{\circ} \mathrm{C}$ for Salmonella spp. The presence of complementary 
DNA prevents aggregation with the addition of $2 \mu \mathrm{HCl} 0.01 \mathrm{~N}$ after $5 \mathrm{~min}$ of incubation at room temperature (the solution remains pink), whereas in the opposite event (no presence of complementary DNA) the color turns into purple. Colour detection was performed visually and was confirmed with an absorption spectrum using Ultraviolet-visible spectroscopy (UV-vis spectrum - Epoch Spectrophotometer, BioTek, 74177, Germany). The solutions were kept for 5-15 $\mathrm{min}$ at room temperature until colour was developed and then they were photographed. All experiments were performed in triplicate.

\subsection{Direct Application on Food Samples}

After optimization using DNA extracted from the isolate cultures, as described in the previous paragraphs, the assay was applied on DNA extracted from food samples, which were found to be contaminated with pathogens causing food-borne infections. More specifically, $15 \mu \mathrm{l}$ of the extracted DNA from the food was added to $10 \mu \mathrm{l}$ of the AuNP-OLG solution, as described above. The colour change was evaluated visually and confirmed with an absorption spectrum. The results were compared to those obtained by PCR assays. In order to assess the repeatability of the method for the specific type of samples, testing with the proposed assay was repeated five times for each DNA extract.

\section{Results and Discussion}

Spherical gold nanoparticles in the size range of 13-20 nm with absorbance peak around $520 \mathrm{~nm}$ have been employed in biosensors due to their ease of synthesis. The AuNP-OLG solution exhibits a pink colour because of surface plasmon resonance at an absorbance peak of $\sim 525 \mathrm{~nm}$. The addition of $\mathrm{HCl}$ enhances the aggregation of AuNP-OLG because of the absence of the specific target of DNA, leading to a change of colour from pink to purple. The changes in colour can be visually detected but also confirmed by aUV-vis spectrum (Willets \& Van Duyne, 2007; Verma, Rogowski, Jones, Frank, \& Gu, 2015). We used this approach and designed an assay that was evaluated in a two-step process, (a) on pure cultures of isolated bacteria (positive controls) and subsequently (b) on food specimens that were found by a reference method to be contaminatedby pathogens causing food-borne infections.

Regarding the pure culture evaluation (first step), the assay produced positive results with all three pathogens tested (S. aureus, L. monocytogenes, and S. enteritidis), and the sensitivity was $100 \%$. We tested our assay in comparison to PCR using serial 10-fold dilutions of the culture positive control DNA, starting from $\mathrm{C}_{1}=12.3$ $\mathrm{ng} / \mu \mathrm{L}$. The lower detection limit (LOD) of our assay was defined at $123 \mathrm{fg} / \mu \mathrm{L}$ of DNA, whereas the respective LOD of the PCR was $1.23 \mathrm{pg} / \mu \mathrm{L}$, thus indicating that the AuNP-OLG assay performed better than the PCR in the range of one 10 -fold dilution.

UV-Vis spectroscopic data for samples (Figure 1) supported the hypothesis of aggregation-induced visual discrimination of the sample and showed an absorbance peak at $520 \mathrm{~nm}$, which was due to the collective excitation of the free conduction band electrons of the dispersed particles, known as the surface plasmon resonance. In contrast, the negative sample's wider absorbance spectrum is indicative of peak shift towards longer wavelength, due to the coupling in the surface plasmons of the particles in the aggregates (Figure 2). Negative results were produced after testing the negative control bacteria E. coli and Y. enterocolitica (Figure 2). The collective plasmon peak was intensified and appeared in a new position between 560 and $800 \mathrm{~nm}$, depending on the degree of aggregation and concentration of AuNPs. The method was repeatable and produced the same results all five times it was performed. The colour density was concentration depended, and final turnaround time was less than 30 minutes. 


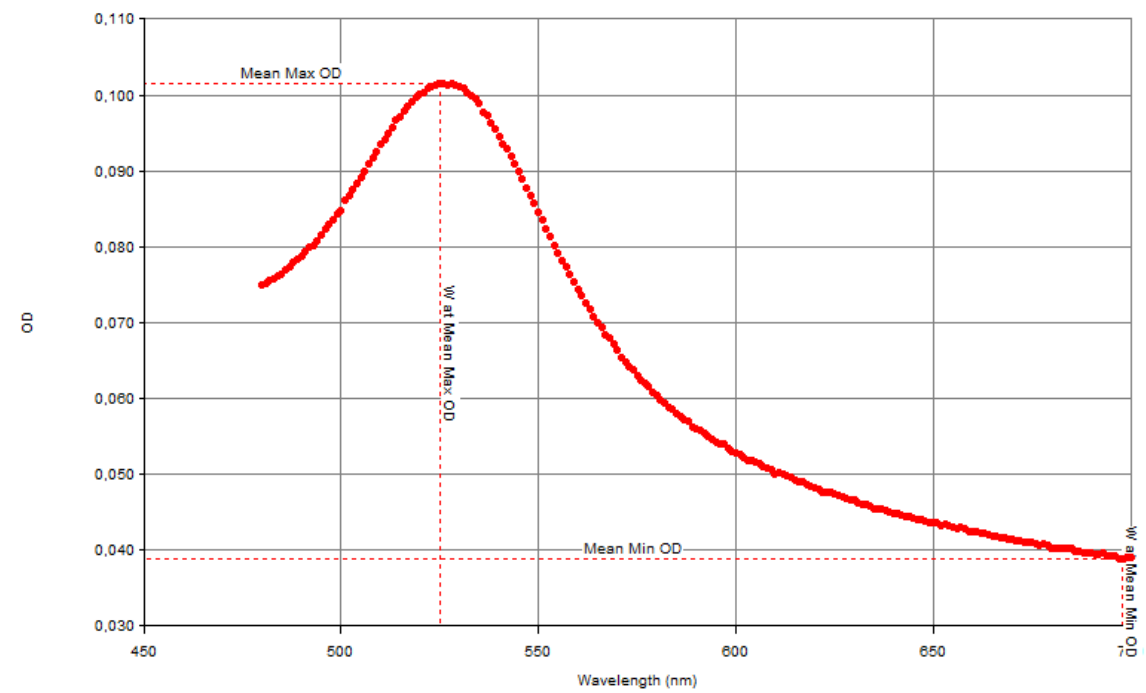

Figure 1. Representative spectrum from the positive sample containing L. monocytogenes genomic DNA, showing characteristic absorbance peak at $520 \mathrm{~nm}$

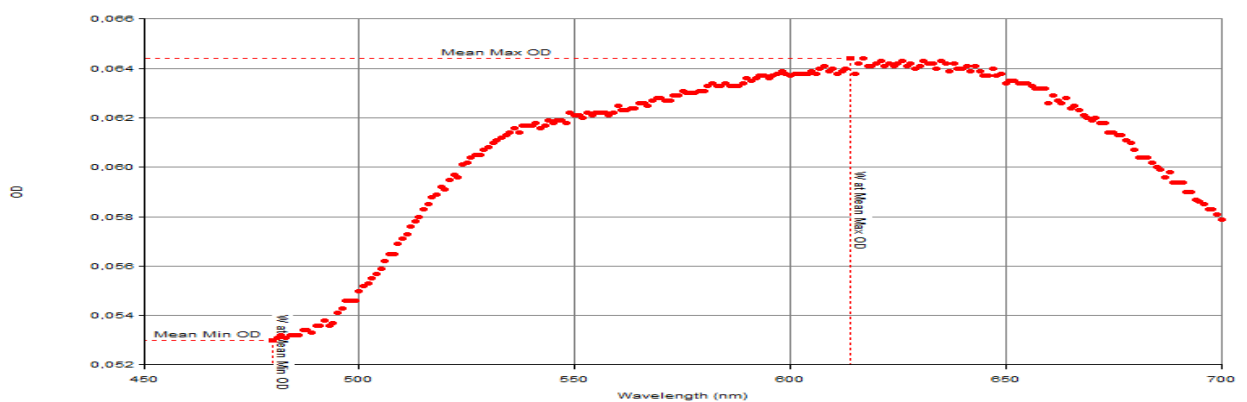

Figure 2.Representative spectrum from a negative sample exhibiting wide length of absorbance and a peak beyond $600 \mathrm{~nm}$

There have been only a few studies focusing on direct detection of bacterial food-borne pathogens using gold nanoprobes that compare different detection methods. A previously described nanoprobe-based study indicated comparable results to those presented here; thus, size $23 \mathrm{~nm}$ gold nanoparticles were able to produce a detection limit of one log lower than the PCR targeting the stn gene of Salmonella spp. (Hitchins, Jinneman, \& Chen, 1998), a difference that was similar to the one observed in our study. In addition, there have been reports about the detection of L. monocytogenes and S. enterica in samples of food and/or beverage by targeting the hly and hut genes, respectively, and in contaminated milk samples using $13 \mathrm{~nm}$ gold nanoparticles (Fu, Zhou, \& Xing, 2013), with similar sensitivity as in the present study. Also, the AuNP-OLG method indicated that it could detect mycobacteria in a reliable and highly specific manner (Liandris et al., 2009; Hussain, Samir, \& Azzazy, 2013), and no crossreactions with related bacteria were observed, as demonstrated effectively after application on faecal samples harbouring mixed bacterial populations. Finally, very recently, gold nanoparticles were combined with ligase-based amplification, resulting in highly specific detection of food-borne pathogens (Wang, Ying, Wei, \& Yuan, 2017), although this approach required additional steps and infrastructure (ligase-based amplification and micro-array detection), whereas the present one is infrastructure-independent.

It should be noted however, that the evaluation in most of these studies was performed mainly on culture isolates. In contrast, our assay was additionally evaluated on 60 food specimens (second step of evaluation). These specimens were identified by a reference microbiological assay to be contaminated with Salmonella spp., S. aureus, or L. monocytogenes. All these specimens were found to be contaminated with a single pathogen each; more specifically, 15 meat products were contaminated with Salmonella spp., 35 milk products were 
contaminated with $S$. aureus, and finally five cheese pies and five ready-made salads were contaminated with $L$. monocytogenes.

All 60 food specimens were positive by the AuNP-OLG assay method and no discrepancies with the reference method were detected (100\% sensitivity). In contrast, discrepant results were obtained by the PCR assay, which was used as a comparison to the nano-probe assay; two dairy products were negative for $S$. aureus and two meat specimens were negative for Salmonella spp. In that respect, PCR did not detect a total of four specimens (6.7\%), resulting in $93.3 \%$ sensitivity. All positive food samples produced the assay's characteristic absorbance peak at $520 \mathrm{~nm}$, with gradual decrease in absorbance relative to the concentration of genomic DNA present in the test sample, whilst the negative ones exhibited the red shift in their spectra, with the absorbance peak being shifted to longer wavelength ( $\geq 600 \mathrm{~nm}$ ), coupled by a peak decrease in $520 \mathrm{~nm}$. An interesting feature of this assay is that the positive samples, when kept overnight at room temperature, continued to retain their colour (data not shown), suggesting the stability of the AuNP-OLG probe hybridization with the DNA sequence, a particularly useful feature for prolonged read-out capability.

One limitation of the present method is that it cannot quantify the bacterial load, whereas culture, or Real-Time PCR using the TaqMan chemistry, can do. Nevertheless, culture has a long turnaround time, and RT-PCR requires expensive instruments and infrastructure. In contrast, UV-vis spectroscopy is usually available in laboratories and can further confirm the visually identified results of the nanoparticles (Jung, Jung, Parab, Li, \& Park, 2010). It should be noted also, that the platform can accommodate detection of many bacterial species simultaneously, allowing multiplexing, high throughput screening and expedite turnaround time of clinical, veterinary and food specimens.

In conclusion, the present study evaluated a highly sensitive and specific assay, on pure culture isolates but also on contaminated food samples, and indicated similar performance to the reference method and better performance than PCR amplification, without the need of using complex instruments and infrastructure.

\section{Acknowledgments}

The present work was supported by the Special Account for Research Grants of the Technological Educational Institution (TEI) of Athens (Project No. 80251/2015).

\section{References}

Agasti, S. S., Rana, S., Park, M-H., Kim, C. K., You, C-C., \& Rotello, V. M. (2010). Nanoparticles for detection and diagnosis. Advanced Drug Delivery Reviews, 62(3), 316-328. https://doi.org/10.1016/j.addr.2009.11.004

Fu, Z., Zhou, X., \& Xing, D. (2013). Rapid colorimetric gene-sensing of food pathogenic bacteria using biomodification-free gold nanoparticle. Sensors and Actuators B: Chemical, 182, 633-641. https://doi.org/10.1016/j.snb.2013.03.033

Gouws, P. A., \& Liedemann, I. (2005). Evaluation of diagnostic PCR for the detection of Listeria monocytogenes in food products. Food Technology and Biotechnology, 43, 201-205.

Hill, H. D., \& Mirkin, C. A. (2006). The bio-barcode assay for the detection of protein and nucleic acid targets using DTT-induced ligand exchange. Nature Protocols, 1(1), 324-336. http://dx.doi.org/10.1038/nprot.2006.51

Hitchins, A. D., Jinneman, K., \& Chen, Y. (1998). Detection of Listeria monocytogenes in Foods an Environmental Samples, and Enumeration of Listeria monocytogenes in Foods. Bacteriological Analytical Manual, $8^{\text {th }}$ Edition, Revision A. U.S. Food and Drug Administration. https://www.fda.gov/Food/FoodScienceResearch/LaboratoryMethods/ucm2006949.htm

Hoorfar, J. (2011). Rapid detection, characterization, and enumeration of foodborne pathogens. APMIS, 119 (Supplement s 133), 1-24. https://doi.org/10.1111/j.1600-0463.2011.02767.x

Hussain, M. M., Samir, T. M., \& Azzazy, H. M. E. (2013) Unmodified gold nanoparticles for direct and rapid detection of Mycobacterium tuberculosis complex. Clinical Biochemistry, 46(7-8), 633-637. https://doi.org/10.1016/j.clinbiochem.2012.12.020

Jung, Y. L., Jung, C., Parab, H., Li, T., \& Park, H. G. (2010). Direct colorimetric diagnosis of pathogen infections by utilizing thiol-labeled PCR primers and unmodified gold nanoparticles. Biosensors and Bioelectronics, 25(8), 1941-1946. https://doi.org/10.1016/j.bios.2010.01.010

Liandris, E., Gazouli, M., Andreadou, M., Čomor, M., Abazovic, N., Sechi, L. A., \& Ikonomopoulos, J. (2009). 
Direct detection of unamplified DNA from pathogenic mycobacteria using DNA-derivatized gold nanoparticles. Journal of Microbiological Methods, 78(3), 260-264.

https://doi.org/10.1016/j.mimet.2009.06.009

McGrath, T. F, Elliott, C. T, \& Fodey, T. L. (2012). Biosensors for the analysis of microbiological and chemical contaminants in food. Analytical and Bioanalytical Chemistry, 403(1), 75-92. https://doi.org/10.1007/s00216-011-5685-9

Newell, D. G., Koopmans, M., Verhoef, L., Duizer, E., Aidara-Kane, A., Sprong, H., ... Kruse, H. (2010). Food-borne diseases - The challenges of 20 years ago still persist while new ones continue to emerge. International Journal of Food Microbiology, 139(S3-S15). https://doi.org/10.1016/j.ijfoodmicro.2010.01.021

Syed, M. A., \& Bokhari, S. H. A. (2011). Gold Nanoparticle Based Microbial Detection and Identification. Journal of Biomedical Nanotechnology, 7(2), 229-237. https://doi.org/10.1166/jbn.2011.1281

Vannuffel, P., Gigi, J., Ezzedine, H., Vandercam, B., Delmee, M., Wauters, G., \& Gala, J. L. (1995). Specific detection of methicillin resistant Staphylococcus species by multiplex PCR. Journal of Clinical Microbiology, 33(11), 2864-2867.

Vasquez-Novel, M. D., Pazos, A. J., Abad, M., Sanchez, J. L., \& Perez-Paralle, M. L. (2005). Eight-hour PCR-based procedure for the detection of Salmonella in raw oysters. FEMS Microbiology Letters, 243(1), 279-283. https://doi.org/10.1016/j.femsle.2004.12.016

Verma, M. S., Rogowski, J.L., Jones, L., Frank, X., \& Gu, F. X. (2015). Colorimetric biosensing of pathogens using gold nanoparticles. Biotechnology Advances, 33(6), 666-680.

https://doi.org/10.1016/j.biotechadv.2015.03.003

Wang, X., Ying, S., Wei, X., \& Yuan, J. (2017). Development of a gold nanoparticle-based universal oligonucleotide microarray for multiplex and low-cost detection of foodborne pathogens. International Journal of Food Microbiology, 253, 66-74. https://doi.org/10.1016/j.ijfoodmicro.2017.05.005.

Willets, K. A., \& Van Duyne, R. P. (2007). Localized surface plasmon resonance spectroscopy and sensing. Annual Review of Physical Chemistry, 58, 267-97. https://doi.org/10.1146/annurev.physchem.58.032806.104607

\section{Copyrights}

Copyright for this article is retained by the author(s), with first publication rights granted to the journal.

This is an open-access article distributed under the terms and conditions of the Creative Commons Attribution license (http://creativecommons.org/licenses/by/4.0/). 